\title{
Dynamic Modeling and Analysis of a High Pressure Regulator
}

\author{
Muhammad Ramzan and Adnan Maqsood \\ Research Centre for Modeling \& Simulation, National University of Sciences and Technology, Islamabad, Pakistan \\ Correspondence should be addressed to Adnan Maqsood; adnan@rcms.nust.edu.pk
}

Received 30 June 2016; Revised 11 October 2016; Accepted 12 October 2016

Academic Editor: Tarek Ahmed-Ali

Copyright (c) 2016 M. Ramzan and A. Maqsood. This is an open access article distributed under the Creative Commons Attribution License, which permits unrestricted use, distribution, and reproduction in any medium, provided the original work is properly cited.

\begin{abstract}
Pressure regulator is a common device used to regulate the working pressure for plants and machines. In aerospace propulsion systems, it is used to pressurize liquid propellant rocket tanks at specified pressure for obtaining the required propellant mass flow rate. In this paper, a generalized model is developed to perform dynamic analysis of a pressure regulator so that constant pressure at outlet can be attained. A nonlinear mathematical model of pressure regulator is developed that consists of dynamic equation of pressure, temperature, equation of mass flow rate, and moving shaft inside regulator. The system of nonlinear and coupled differential equations is numerically simulated and computation of pressure and temperature is carried out for required conditions and given design parameters. Valve opening and mass flow rate are also found as a function of given inlet pressure and time. In the end, an analytical solution based on constant mass flow rate assumption is compared with nonlinear formulation. The results demonstrate a high degree of confidence in the nonlinear modeling framework proposed in this paper. The proposed model solves a real problem of liquid rocket propulsion system. For the real system under consideration, inlet pressure of regulator is decreased linearly from 150 bar to 60 bar and outlet pressure of nearly 15 bar is required from pressure regulator for the complete operating time of $19 \mathrm{~s}$.
\end{abstract}

\section{Introduction}

Pressure regulator is normally a dynamic open valve that takes a high varying inlet pressure and converts it to a nearly constant and lower desired outlet pressure. It consists of set screw, working spring, main shaft, valve seat, inlet outlet chamber, sensing orifice, pressure chamber, rolling diaphragm plate, and return spring as shown in Figure 1. Constant downstream pressure is obtained by variable valve opening area. This variable valve opening area is generated due to opposite force balancing between spring loading and pressure acting on diaphragm plate in pressure chamber. Rolling diaphragm moves upwards as downstream pressure increases and moves backward as downstream pressure decreases for maintaining constant outlet pressure.

Vujic and Radojkovic [1] studied the procedure of forming nonlinear dynamic model of gas pressure regulator. The model showed the self-exciting oscillations of systems with certain amplitude and frequency without the presence of outside disturbance. The results reported the effect of each design parameter for self-exciting oscillations and suggested methods to correct them. In the end, it was proposed that a linear model is sufficient for evaluation of stability and transient response if flow through valve is laminar, dry friction is negligible, and the motion of valve and diaphragm is not constrained. These sets of assumptions are significantly contradictory to actual operations. Specifically, mixing triggers a highly turbulent phenomenon inside pressure regulators and the situation further worsens under high pressure environments. Similarly, Sunil et al. [2] developed the linear mathematical model of pressure regulator for cryogenic application pressure regulator. The model was validated with the experimental test of cryogenic pressure regulator, developed by Liquid Propulsion Systems Centre (LPSC) of Indian Space Research Organization. The effect of cryogenic temperature was measured in the regulated pressure taking into account spring load variation, design changes, and fluid property. It is interesting to note that the pressure differential equation in regulator flow volume was considered without taking the valve clearance factor and assuming the constant temperature in all regulator volumes in both studies. 


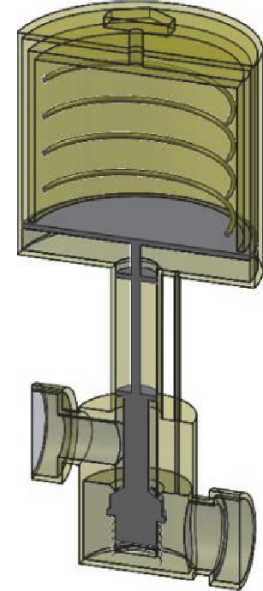

(a)

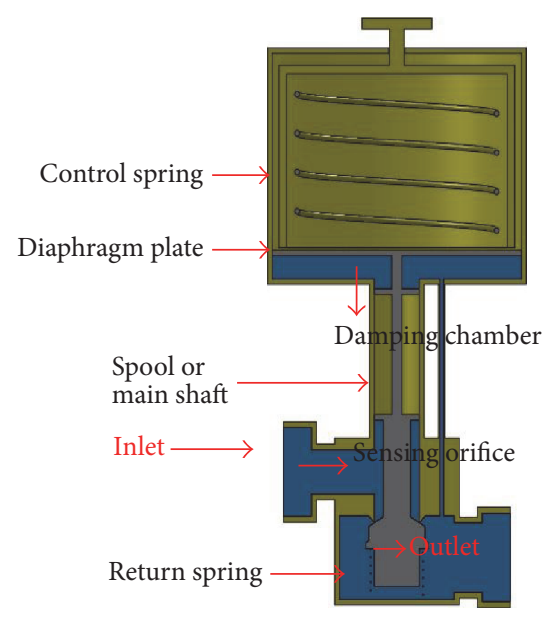

(b)
Figure 1: Cross-sectional view of pressure regulator and its components: three-dimensional view (a) and two-dimensional cross section (b).

Shahani et al. [3] studied the dynamic equation of pressure and temperature with the assumption of adiabatic process happening in high pressure regulator. The model was simulated using numerical tools and verified experimentally. It was found that as outlet volume increases, the stability of outlet pressure increases and as spring load increases, outlet pressure increases proportionally. The control spring stiffness and diaphragm area were two sensitive parameters identified that effect downstream pressure of regulator. It was suggested that, for the better control of outlet pressure of regulator, these two parameters should be designed and manufactured carefully.

Zafer and Luecke [4] investigated the stability characteristics and showed the cause of vibration and possible design modification for eliminating the unstable vibrating model. A comprehensive linear dynamic model of self-regulating high pressure gas regulator was developed for stability analysis. Root locus technique was used to study the effect of variation of various design parameters on system dynamics. It was concluded that damping coefficient, the diaphragm area, and upper and lower volumes are most important design parameters that affect the stability. An improvement in stability was reported with the decrease in flow path between regulator body and lower pressure chamber. Similarly, Delenne and Mode [5] performed experimental and numerical simulation to identify the relative influence of several parameters on emergence and amplitude of oscillations. However, no discussion on regulator design and model parameters is made. Experimental work performed in various studies cannot be extended as they give results subject to specific geometric shape.

Rami et al. [6] developed mathematical model, performed experimental analysis, measured performance, and found operating conditions that increase stability. The numerical and experimental results were in good agreement with respect to each other. It was concluded that oscillations in downstream pressure increase for small volumes and higher upstream pressure. The study showed that opening of valve and driving pressure have less effect on oscillation of downstream pressure. Moreover, the length of sensing lines from downstream chamber to damping chambers of regulator has only little influences on the oscillation of downstream pressure.

With the advancement of Computational Fluid Dynamics (CFD), several studies are directed towards complex flow generation and visualization inside pressure regulator. Shipman et al. [7] carried steady and unsteady simulation for the analysis of gas pressure regulator for rocket feed system. Comparison of the numerical results and experimental data from NASA Stennis Space Center was found to be satisfactory. Ortwig and Hubner [8] worked on mechatronic pressure controller for Compressed Natural Gas (CNG) engines. CFD simulation for analysis of shock and vortices formation near the valve opening was performed and potential for the improvement in geometry with the help of CFD results was discussed. It was concluded that flow forces are dependent on pressure differential. Moreover, steady state flow forces are almost independent of valve opening. Saha [9] performed the numerical simulation of a pressure regulated valve to find out the characteristics of passive control circuit. Commercial software was used to analyze the flow forces on different interfaces of the moving shaft of regulator. A special User Defined Function (UDF) for varying inlet pressure and reducing the valve opening by delta amount for transient analysis of pressure regulator was written. Flow convergence was checked at each time step using UDF and calculation was allowed to move to next time step only after meeting the required criteria for convergence. Similarly, Du and Gao [10] carried numerical study of complex turbulent flow through valves in a steam turbine system. Their main aim was to understand the flow behavior through the complex configuration operating under different conditions, so as to derive the necessary information of optimizing the valve design. However, dynamic prediction cannot be performed using CFD simulations as they are very expensive and not practical in real-time environment. The model presented in this paper tries to fill this void.

From operations perspective, Yanping et al. [11] discussed the dynamic model of pressure reducing valve. The dynamic processes of valve for pressurizing, startup, and different operating conditions by numerical simulations and experimental investigation were discussed. It was concluded that increasing the area of damping hole or decreasing the volume of damping cavity can not only reduce redressing time of the pressure regulating valve, but also reduce overshoot. Moreover, increasing the stiffness of the main spring can reduce the redressing time of the pressure regulating valve. From review of relevant studies, it is clear that a complex phenomenon occurs inside pressure regulator that includes compressibility, choking, turbulence, fluid structure interaction, flow expansion with recirculation, and flow separation.

There is dearth of published literature which briefly discusses the dynamic simulation of high differential pressure regulator. In this study, a generalized nonlinear mathematical model is developed that computes regulator outlet pressure by 
incorporating at the same time the dynamic equation of valve clearance, differential equation of temperature in regulator volume, and equation of mass flow rate by finding pressure gradients in the inlet volume and outlet volume as a function of time. Model is simulated for two cases. For the first case, the inlet pressure of reservoir is increased from 60 bar to 150 bar at the rate of $4.74 \mathrm{bar} / \mathrm{s}$. Results of pressure, temperature, mass flow rate, and valve opening are computed. The model is of utilitarian nature and is specifically simulated for particular application in rocket tank feed system for propulsion of rocket in second case. Specifically, the reservoir pressure is reduced from $150 \mathrm{bar}$ to $60 \mathrm{bar}$ at the rate of $4.74 \mathrm{bar} / \mathrm{s}$ and model is simulated for $19 \mathrm{~s}$ for controlling outlet pressure near 15 bar. Mass flow rate and valve opening are required as a function of time for maintaining 15-bar pressure at outlet port with respect to varying high inlet pressure. Initial parameters of regulator are set in a way that it gives initial valve opening of $2.3 \mathrm{~mm}$. With the known value of constant mass flow rate for varying high inlet pressure and keeping constant temperature at inlet and outlet, an analytical solution is also proposed for dynamic equation of pressure with varying high inlet pressure as a function of time.

\section{Geometric Description}

A pressure regulator normally consists of tightening screw on its top to provide the load force on working spring. This load force controls the outlet pressure. Other main parts are inner moving shaft with valve whose basic function is to restrict the flow and provide a function of pressure drop.

Overall flow volume of pressure regulator is divided into four regions and for each flow volume (Figure 2), we developed mathematical model for pressure and temperature as a function of time. First-order forward differencing scheme is used for the discretization of dynamic equation of pressure and temperature. Equation of moving inner shaft is reduced to two sets of first order differential equations with initial conditions and computed numerically using Runge-Kutta method. Mass flow rate, valve opening, and outlet pressure are computed as a function of time and inlet pressure. An analytical solution is found for finding controlled outlet pressure as a function of time with some assumptions.

Here $V_{\text {in }}$ is the inlet volume, $V_{1}$ is intermediate volume, $V_{\text {out }}$ or $V_{\text {reg }}$ is outlet volume, and $V_{\text {dam }}$ is the damping volume in cubic meter. $P$ (bar) and $T$ (Kelvin) are pressure and temperature in corresponding volumes. $\dot{m}_{\mathrm{in}}$ is the inlet mass flow rate $(\mathrm{kg} / \mathrm{s})$ from high pressurized compressed air cylinder to inlet volume and other mass flow rates correspond to flow from one volume to another volume (Figure 3).

\section{Mathematical Modeling}

For the development of dynamic equation of pressure we use the assumption of adiabatic and reversible process inside regulator ducts, so we can use the isentropic relation between pressure $(P)$, density, and specific heat ratio $(\gamma)$

$$
P\left(\frac{V}{M}\right)^{\gamma}=\text { const. }
$$

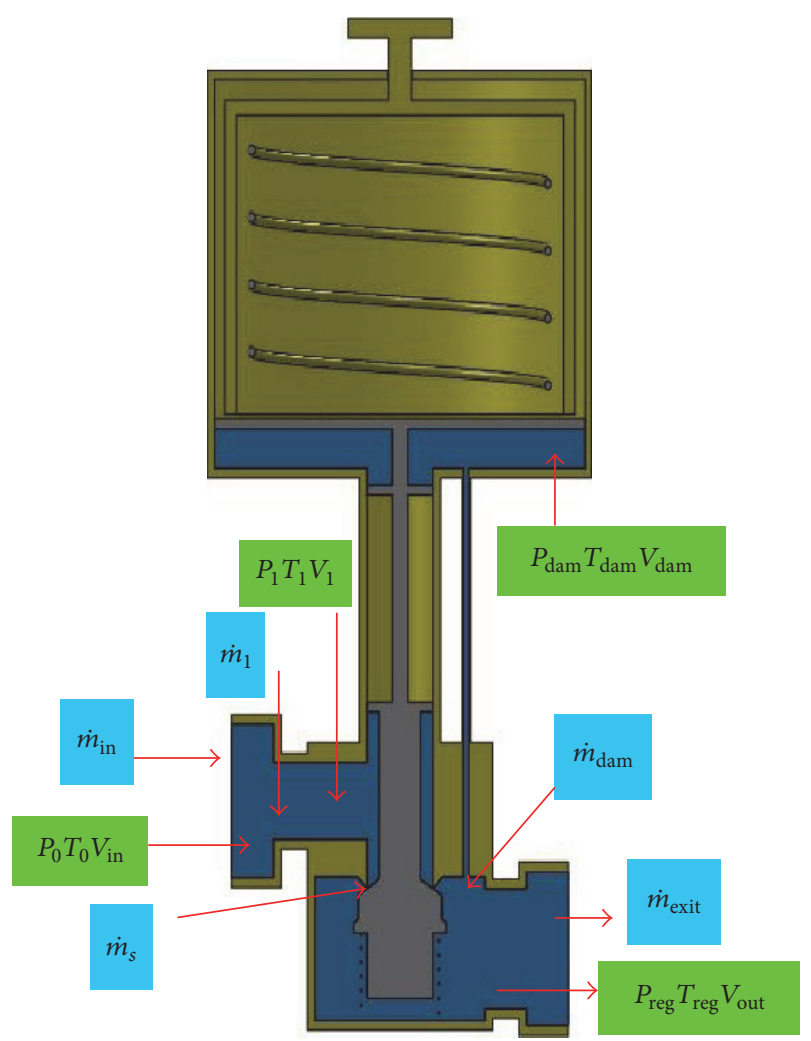

FIGURE 2: Flow volumes of pressure regulator and corresponding quantities.

It is pertinent to note that the entire volume is divided into four subvolumes, $V_{\text {in }}, V_{1}, V_{\text {out }}$, or $V_{\text {reg }}$ and $V_{\text {dam }} . V_{\text {in }}$ here is the inlet volume, $V_{1}$ is intermediate volume, $V_{\text {out }}$ or $V_{\text {reg }}$ is outlet volume, and $V_{\text {dam }}$ is damping volume. Differentiating with respect to time and after simplification, dynamic equation of pressure is found and is given in

$$
\frac{d P}{d t}=\left(\frac{R \gamma}{V}\right) *\left(T_{\text {in }} \dot{m}_{\text {in }}-T_{\text {out }} \dot{m}_{\text {out }}+T_{s} \dot{m}_{s}\right)-\frac{\gamma A P}{V} \dot{x},
$$

where $A$ is the valve clearance area, $x$ is the valve clearance length in $\mathrm{mm}, R$ is the ideal gas constant, $T_{\text {in }}$ is the inlet temperature, $T_{\text {out }}$ is the outlet temperature, $T_{s}$ is the temperature of damping orifice, and $m_{s}$ is the mass flow through damping orifice.

Development of dynamic equation of temperature is carried out from first law of thermodynamics. Considering the density change is occurring in regulator duct, we can write sum of all energy added to ducts of pressure regulator by the energy equation as

$$
\frac{d}{d t} E+\frac{d}{d t} W=\frac{d}{d t} Q+\dot{H}_{\text {in }}-H_{\text {out }},
$$

where $E$ represent total internal energy, $W$ is the rate of change of work, and $Q$ is heat transfer inside and outside of pressure regulator. Here we are assuming that no heat transfer is taking place. $\dot{H}_{\text {in }}$ and $\dot{H}_{\text {out }}$ are the inlet and outlet enthalpy of air mass in regulator ducts. After simplification of 


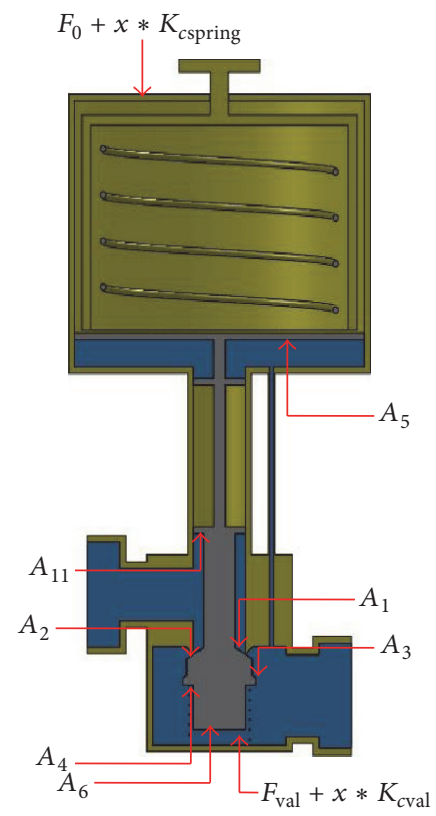

FIGURE 3: Force balance on various area of moving shaft.

energy equation, following dynamic equation of temperature is found:

$$
\frac{d}{d t} T=\left(\frac{R T_{\text {out }}}{P_{\text {out }} V_{\text {out }}}\right)^{2}
$$

$$
\begin{aligned}
& *\left[\left(\gamma \frac{T_{\text {in }}}{T_{\text {out }}}-1\right) \dot{m}_{\text {in }}-(\gamma-1) \dot{m}_{\text {out }}\right] \\
& -\frac{(\gamma-1) P}{V_{\text {out }}} A \dot{x} .
\end{aligned}
$$

For the mass flow from one flow volume to other, following equation is used:

$$
\begin{aligned}
& \text { if } P_{\text {out }} / P_{\text {in }}<0.528 \\
& \qquad \dot{m}=C A\left(\frac{2}{\gamma+1}\right)^{1 /(\gamma-1)} \sqrt{\frac{2 \gamma}{\gamma+1} \frac{1}{R T_{\text {in }}}} P_{\text {in }} ; \\
& \text { if } P_{\text {out }} / P_{\text {in }}>0.528 \\
& \dot{m}=C A \sqrt{\frac{2 \gamma}{\gamma-1} \frac{1}{R T_{\text {in }}}} P_{\text {in }} \sqrt{\left(\frac{P_{\text {out }}}{P_{\text {in }}}\right)^{2 / \gamma}-\left(\frac{P_{\text {out }}}{P_{\text {in }}}\right)^{(\gamma+1) / \gamma}},
\end{aligned}
$$

where $C$ is the discharge coefficient and its value can be taken as $0.8,0.9$, or 1 . $A$ is the corresponding cross section area for mass flow from one volume to another. Equation of moving shaft is developed from Newton formulation based on its upward and downward motion and is given by

$$
\begin{aligned}
\ddot{x} & =\frac{\left(A_{11} P_{\text {in }}-A_{1} P_{\text {in }}-A_{2} P_{\text {reg }}-A_{3} P_{\text {reg }}+A_{4} P_{\text {reg }}+A_{5} P_{\text {reg }}+A_{6} P_{\text {reg }}-F_{c} \operatorname{sign}(\dot{x})-K_{c s p r i n g} x-F_{0}-F_{\text {valve }}-K_{c v a l v e} x\right)}{M}, \\
x(0) & =2.3 \mathrm{~mm}, \\
\dot{x}(0) & =0,
\end{aligned}
$$

where $K_{c \text { spring }}$ and $K_{c \text { valve }}$ are the control springs and return spring rates. $M$ is the mass of moving shaft and $P_{\text {in }}$ is the inlet pressure. $P_{\text {reg }}$ is the regulated pressure or outlet pressure. $F_{0}$ is the control spring preload or initial force set on spring. $F_{\text {valve }}$ is the return spring precompression. $F_{c}$ is dry friction between shaft seal and regulator. It is also called lubricated or coulomb friction. Also here sign is a MATLAB ${ }^{\circledR}$ signum function which gives the moving shaft opposite direction by observing its velocity.

For all four volumes, derivatives of pressure and temperature are replaced by their time differencing for computation of pressure and temperature. Here the discretized equation of pressure and temperature for outlet volume based on firstorder forward differencing scheme is shown in (8) and (9), respectively:

$$
\begin{aligned}
& P_{\text {reg }}(t+\Delta t)=\left[\left(\frac{R \gamma}{V_{\text {reg }}}\right)\right. \\
& *\left(T_{\text {in }}(t) \dot{m}_{\text {in }}(t)-T_{\text {out }}(t) \dot{m}_{\text {out }}(t)+T(t)_{s} \dot{m}_{s}(t)\right) \\
& \left.\quad-\frac{\gamma A_{s} P(t)}{V_{\text {reg }}} x \dot{(}(t)\right] * \Delta t+P_{\text {reg }}(t),
\end{aligned}
$$

$$
\begin{aligned}
& T_{\text {reg }}(t+\Delta t)=\left[\left(\frac{R T_{\text {out }}^{2}(t)}{P_{\text {out }}(t) V_{\text {out }}}\right)\right. \\
& *\left[\left(\gamma \frac{T_{\text {in }}(t)}{T_{\text {out }}(t)}-1\right) \dot{m}_{\text {in }}(t)-(\gamma-1) \dot{m}_{\text {out }}(t)\right] \\
& \left.-\frac{(\gamma-1) P(t)}{V_{\text {out }}} A_{\text {exit }} x \dot{(}(t)\right] * \Delta t+T_{\text {reg }}(t) .
\end{aligned}
$$

\section{Simulation Results and Discussion}

Above nonlinear and coupled differential equations of each flow volumes are simulated numerically by finite difference method. Second-order differential equation of moving shaft is converted to two sets of first-order differential equations and solved numerically by MATLAB built-in routine ode 45 based on Runge-Kutta method.

Simulation results have been derived for two cases. In first case, we increase the inlet pressure of reservoir from $60 \mathrm{bar}$ to $150 \mathrm{bar}$ at the rate of $4.74 \mathrm{bar} / \mathrm{s}$ and note the outlet pressure of regulator. In second case, pressure in 


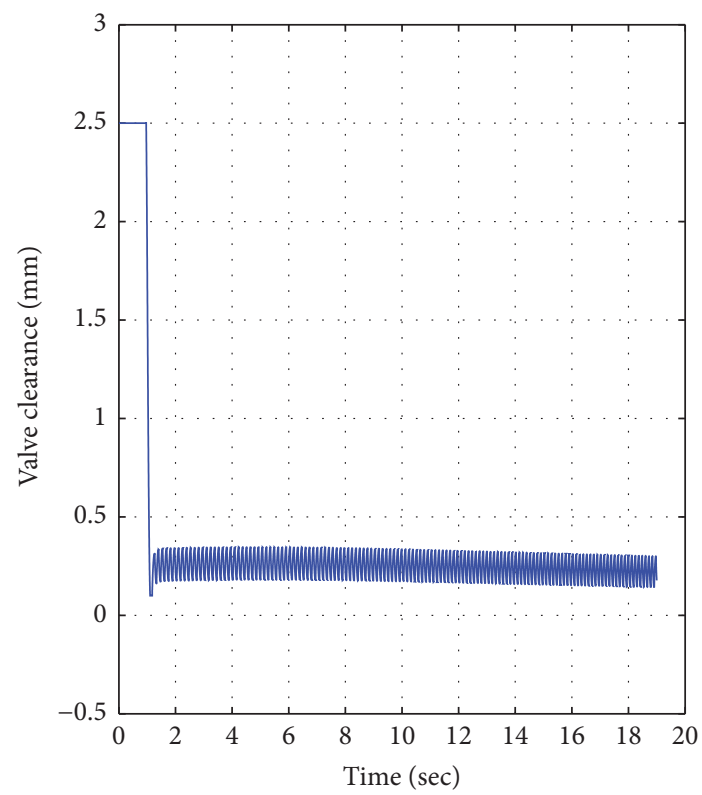

FIGURE 4: Valve opening as a function of time for increasing inlet pressure.

the reservoir or compressed air cylinder is reduced from $150 \mathrm{bar}$ to $60 \mathrm{bar}$ at the rate of $4.74 \mathrm{bar} / \mathrm{s}$ and overall regulator performance is checked corresponding to outlet pressure. For each case, outlet pressure, mass flow rate, temperature, and valve opening are computed.

4.1. Increasing Inlet Pressure from 60 bar to 150 bar. Load or control spring compression on pressure regulator is initially set in such a way that initial valve clearance of regulator is $2.5 \mathrm{~mm}$. When the inlet valve of regulator is opened, high pressure fluids begin to flow from reservoir to different volume of regulator. Pressure in each volume of regulator begins to increase. The pressure in outlet volume is continuously checked in damping chamber through damping orifice. As the pressure in the outlet volume of regulator reaches above 15 bar, pressure creates a force on the diaphragm plate against the load force of spring which was set for a 15-bar pressure at the outlet. As a result, the main shaft of regulator moves upward and valve clearance reaches its minimum opening position. After that, the moving shaft of regulator oscillates up and down such that pressure of nearly 15 bar is maintained in outlet volume of regulator as shown in Figure 4. The outlet pressure approaches to $15 \mathrm{bar}$ around $0.8 \mathrm{~s}$ and valve opening reduces to its minimum level. Steady state oscillations of about $0.25 \mathrm{~mm}$ are observed afterwards. The magnitude of oscillation is about $0.1 \mathrm{~mm}$ which is negligible.

Initial pressure at outlet was 1 bar, near about 0.8 seconds, and outlet pressure reaches 15 bar and then a minor oscillation in outlet pressure is seen for whole simulation time in Figure 5.

Initial valve clearance was $2.5 \mathrm{~mm}$ due to which high mass flow rate is seen initially form volume $V_{1}$ to volume $V_{\text {out }}$. As the pressure in volume $V_{\text {out }}$ reaches 15 bar, the valve opening reduces and a sudden decrement in mass flow rate can be seen

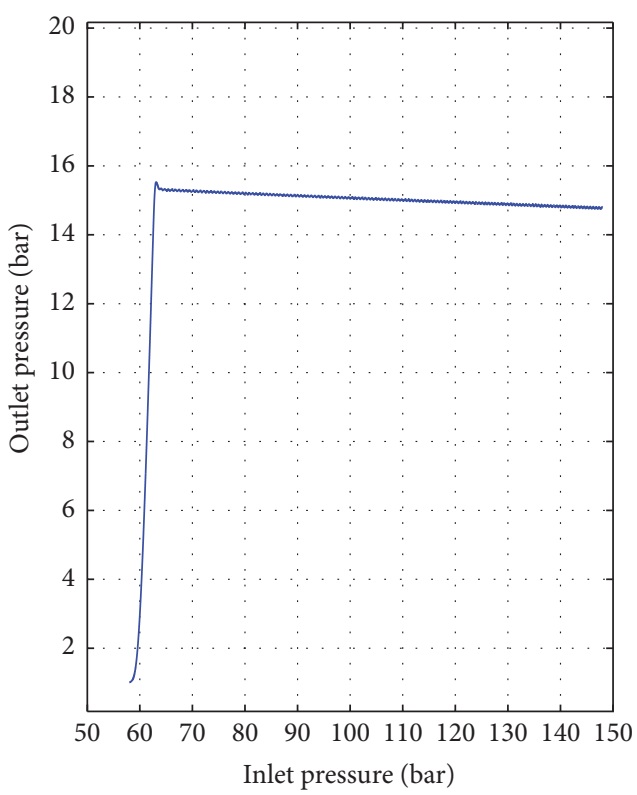

FIGURE 5: Outlet pressure $\left(\mathrm{N} / \mathrm{m}^{2}\right)$ variation against inlet pressure $\left(\mathrm{N} / \mathrm{m}^{2}\right)$ and over entire simulation time.

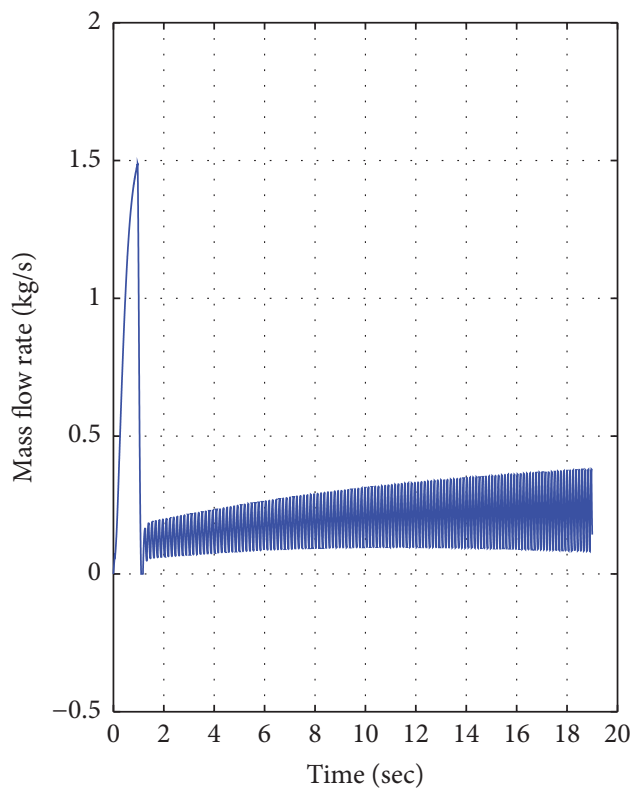

FIGURE 6: Mass flow rate at valve opening as a function of time.

in Figure 6. Subsequently, mass flow rate value oscillates near about $0.24 \mathrm{~kg} / \mathrm{s}$ for maintaining nearly 15 bar at outlet.

Initial temperature of volume $V_{\text {out }}$ was $290 \mathrm{~K}$ (standard atmosphere temperature). With the increase in pressure from 1 to 15 bar, temperature also increases. Due to compressibility effect, temperature does not decrease sharply but it decreases smoothly as shown in Figure 7.

4.2. Decreasing Inlet Pressure from 150 bar to 60 bar. This case corresponds to simulation of real problem of liquid propulsion system. Initial pressure and temperature in each 


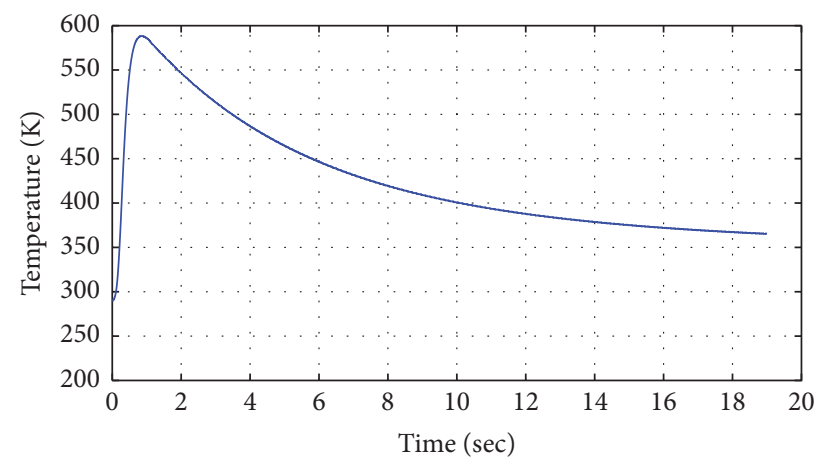

Figure 7: Temperature in outlet volume as a function of time.

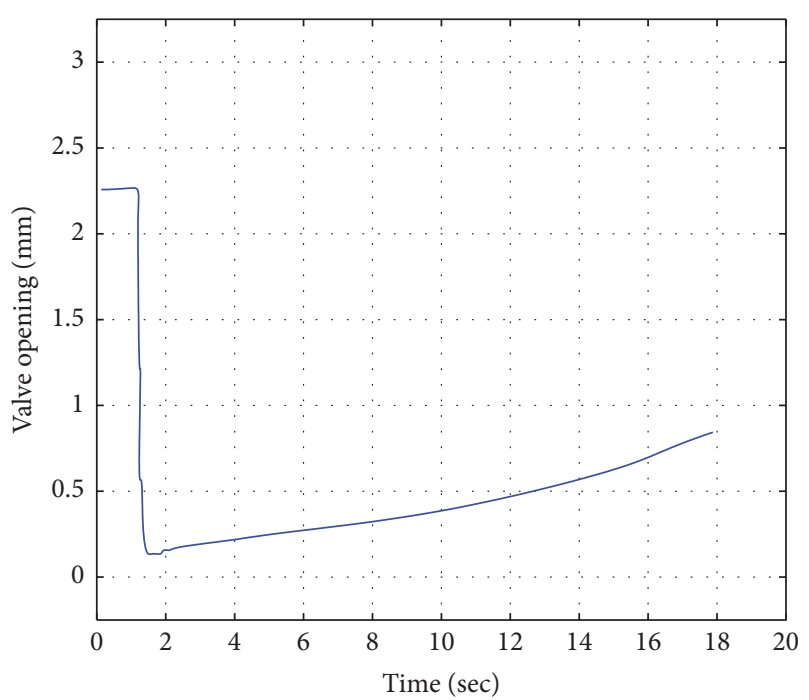

Figure 8: Valve opening as a function of time.

flow volume are taken as 1 bar and $290 \mathrm{~K}$. Time increment $(\Delta t)$ is taken as $0.001 \mathrm{~s}$. Valve opening (Figure 8) is $100 \%$ $(2.3 \mathrm{~mm})$ nearly for $0.7 \mathrm{~s}$. Afterward outlet pressure reaches nearly 15 bar and valve opening reaches its minimum level. Valve clearance value oscillates with magnitude of $0.02 \mathrm{~mm}$ and increases as well with the decrement of inlet pressure to meet the mass conservation.

Initially pressure at outlet volume is 1 bar and after nearly $0.7 \mathrm{~s}$, pressure at outlet reaches average value of $15 \mathrm{bar}$ and control spring load force on diaphragm plate is balanced by pressure force on diaphragm plate in opposite direction. Thus a controlled pressure of nearly 15 bar is achieved as shown in Figure 9.

Initially mass flow rate increases till about $0.7 \mathrm{~s}$ and pressure at outlet volume reaches $15 \mathrm{bar}$, valve clearance decreases, and suddenly mass flow rate also decreases as shown in Figure 10.

Initial temperature was set to $290 \mathrm{~K}$ at outlet volume with pressure of 1 bar. Due to sudden increase of pressure in outlet chamber, average value of temperature suddenly increases for very short time and then steady state temperature reaches due to maintained pressure at outlet as shown in Figure 11.

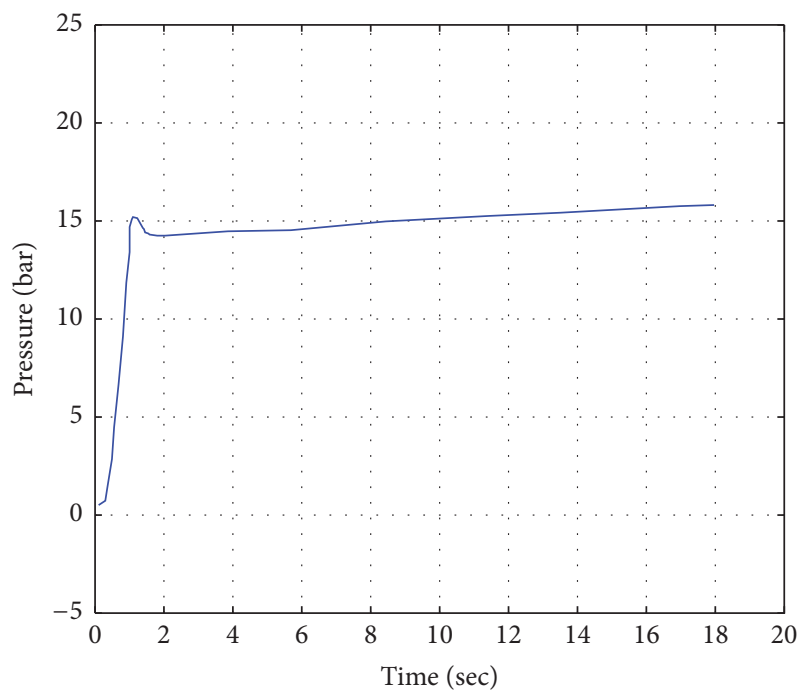

FIgURE 9: Outlet pressure for whole simulation time.

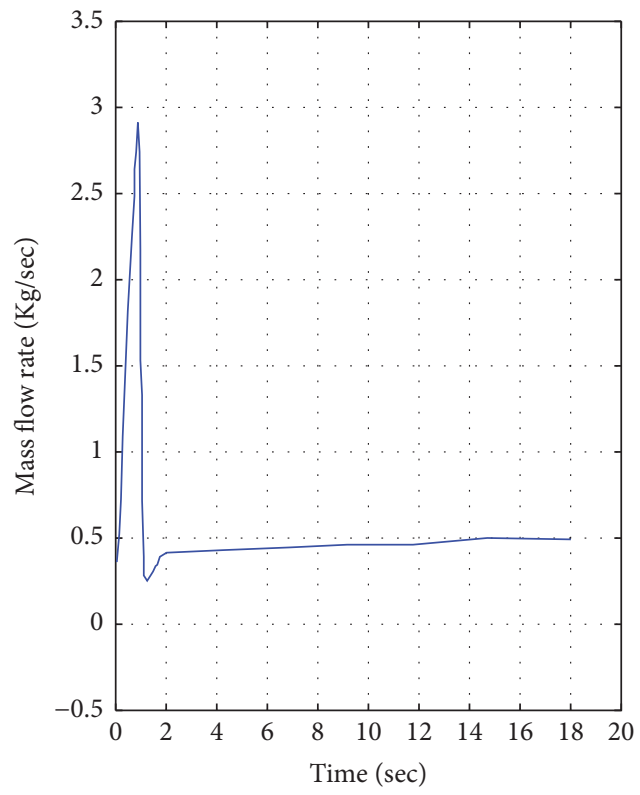

FIGURE 10: Mass flow rate as a function of time.

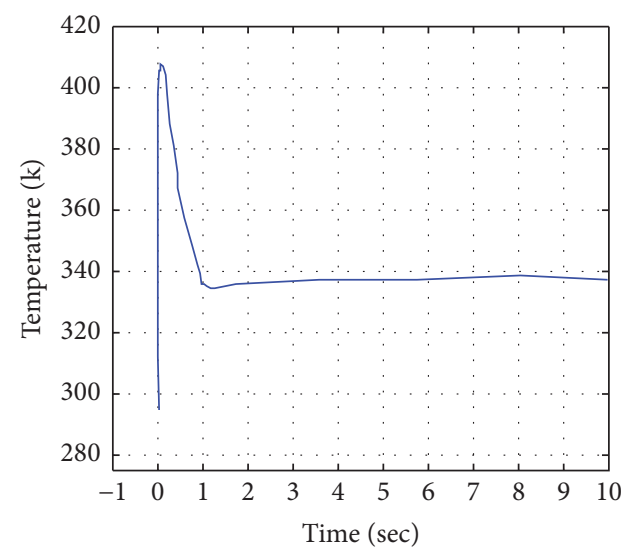

FIGURE 11: Variation of temperature in outlet volume. 


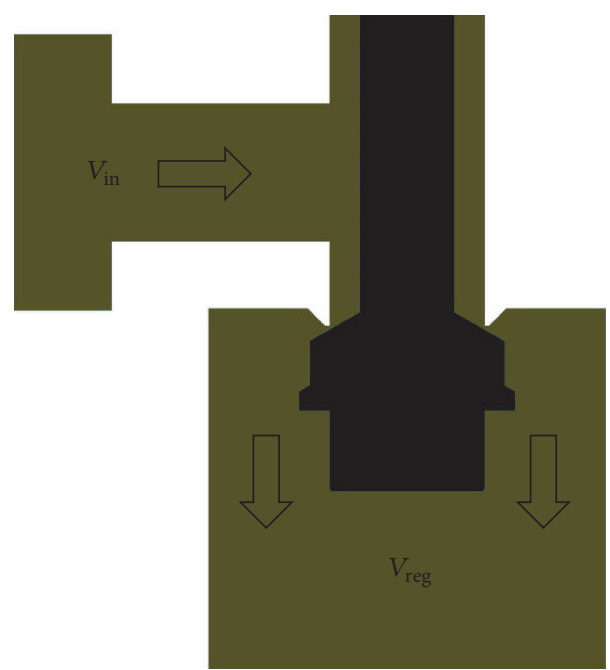

FIGURE 12: Two main flow volumes of pressure regulator used for analytical estimation.

\section{Closed Form Solution of Pressure Equation}

For quick analysis of outlet pressure without involving the full design parameters, an analytical solution of dynamic equation of pressure is obtained with some assumption of constant mass flow rate and different inlet and outlet temperature. For the development of analytical solution only two flow volumes are taken. Inlet volume $V_{\text {in }}$ is the flow volume before the valve opening and outlet volume or regulated volume $V_{\text {reg }}$ is the volume after the valve opening as shown in Figure 12.

By assuming average value of mass flow rate and using mass flow rate equation, valve opening from 150 bar to $60 \mathrm{bar}$ inlet pressure is found as function of time in (10) and is shown in Figure 13. Here valve opening for analytical solution is compared with numerical computed valve opening when outlet pressure reaches nearly 15 bar. The difference in results is due to use of variable mass flow rate with full design parameters in numerical computation and only constant average mass flow rate with different inlet and outlet temperature for analytical solution.

$$
\begin{aligned}
& A(t) \\
& =\frac{\dot{m}}{\left[C_{\mathrm{din}}(2 /(\gamma+1))^{1 /(\gamma-1)} \sqrt{(2 \gamma /(\gamma+1))\left(1 / R T_{\mathrm{in}}\right)} P_{\mathrm{in}}(t)\right]} .
\end{aligned}
$$

Introduced in dynamic equation of pressure, a linear differential equation is obtained which is solved analytically and solution is given by

$$
\begin{aligned}
P_{r}(t)= & \frac{\gamma R}{V_{r}}\left(\sqrt{T_{\text {in }}} A_{s}(t) C_{1} P_{\text {in }}(t)\right) * e^{-A_{e} * \sqrt{T_{\text {out }}} * C_{1}} \\
& +C * e^{-A_{e} * \sqrt{T_{\text {out }}} * C_{1}} \\
C_{1}= & \frac{2}{\gamma+1}^{\gamma /(\gamma-1)} * \sqrt{\frac{2 \gamma}{R(\gamma+1)}},
\end{aligned}
$$

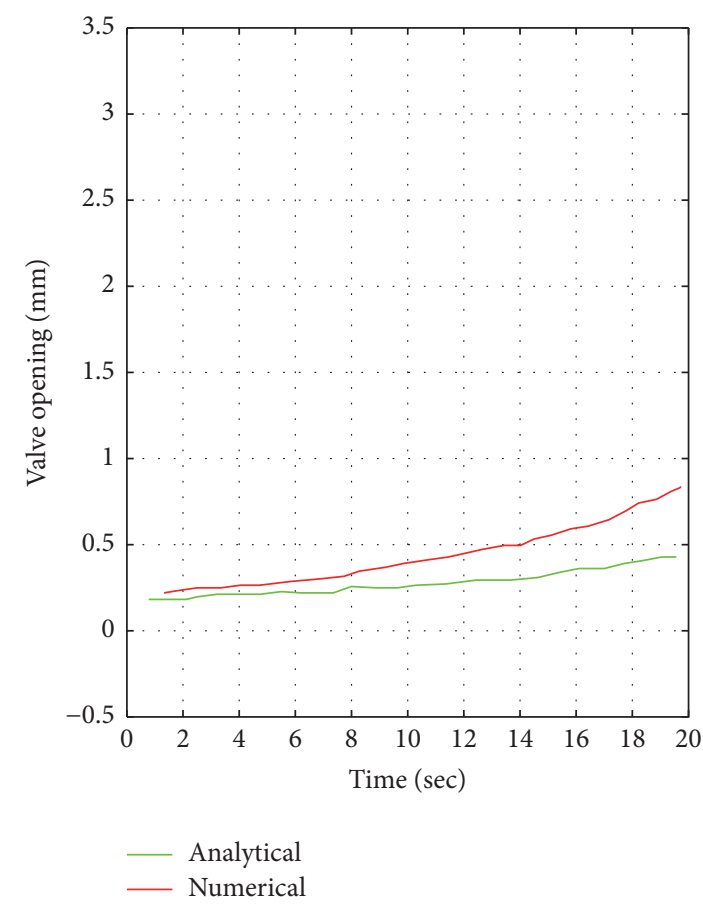

FIGURE 13: Comparison of valve opening as a function of time.

$$
\begin{aligned}
C= & P_{r}(0)-\frac{\gamma R}{V_{r}}\left(\sqrt{T_{\text {in }}} A_{s}(0) C_{1} P_{\text {in }}(0)\right) \\
& * e^{A_{e} * \sqrt{T_{\text {out }}} * C_{1}} .
\end{aligned}
$$

Outlet pressure from numerical computation is compared with analytical solution as shown in Figure 14. Average constant mass flow rate used in valve opening in analytical solution does not provide any oscillation in mass flow rate so here outlet pressure smoothly reaches 15 bar in case of analytical solution for whole simulation time. This is because when the constant mass flow rate assumption is taken then valve opening is only the function of inlet pressure and inlet temperature. In this way we are here ignoring the equation of moving shaft and finding valve opening from the mass flow rate equation. The constant mass flow rate in steady state condition can be used just for quick analysis of some initial design parameters.

\section{Conclusion}

Mathematical model for flow inside a generic pressure regulator is developed and numerically simulated. Dynamic equation of pressure and temperature is developed based on the continuity and energy equation to capture the pressure and temperature change in regulator ducts as a function of time. Equation of moving shaft is developed by Newton second law of motion. First-order forward differencing technique is used to discretize the dynamic equations. Results include dynamic simulation of pressure, mass flow rate, temperature, and valve opening as a function of time and 


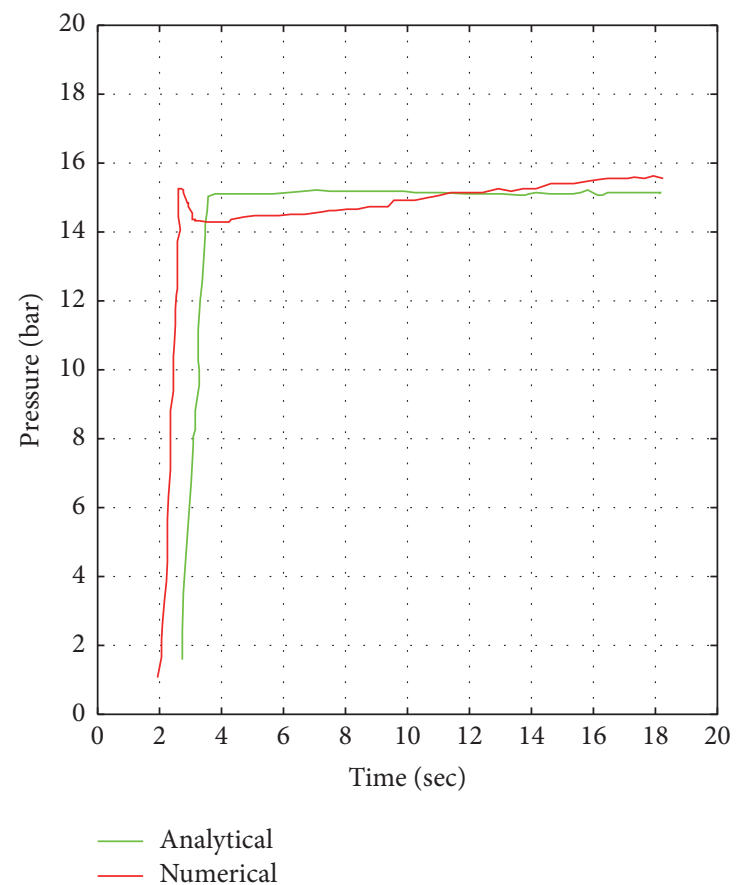

FIGURE 14: Comparison of outlet pressure with time.

inlet pressure. Two scenarios are simulated. In the first case, inlet pressure is increased from 60 bar to 150 bar and 15 bar is maintained at outlet. In second case, inlet pressure is decreased from 150 bar to 60 bar while maintaining outlet pressure of 15 bar. Oscillating mass flow rate with average value of $0.4547 \mathrm{~kg} / \mathrm{s}$ is found for outlet pressure of $15 \mathrm{bar}$. The analytical solution is presented in the end and satisfactory comparison is demonstrated with numerical results.

\section{Competing Interests}

The authors declare that there is no conflict of interests regarding the publication of this paper.

\section{References}

[1] D. Vujic and S. Radojkovic, "Dynamic model of gas pressure regulator," Mechanics, Automatic Control \& Robotics, vol. 3, no. 11, pp. 269-276, 2001.

[2] S. Sunil, U. Pandey, B. S. Jeevanlal, M. Radhakrishnan, and C. Amarasekaran, "Mathematical modeling of pressure regulator for cryogenic applications," in Proceedings of the 37th National \& 4th International Conference on Fluid Mechanics and Fluid Power, FMFP10-CF-30, Chennai, India, December 2010.

[3] A. R. Shahani, H. Esmaili, A. Aryaei, S. Mohammadi, and M. Najar, "Dynamic simulation of high pressure regulator," Journal of Computational and Applied Research in Mechanical Engineering, vol. 1, no. 1, pp. 17-28, 2011.

[4] N. Zafer and G. R. Luecke, "Stability of gas pressure regulators," Applied Mathematical Modelling, vol. 32, no. 1, pp. 61-82, 2008.

[5] B. Delenne and L. Mode, "Modeling and simulation of pressure oscillations in a gas pressure regulator," Proceedings of American Society of Mechanical Engineers, vol. 7, 2000.
[6] E. G. Rami, B. Jean-Jacques, G. Pascal, and M. Francois, "Stability study and modeling of a pilot controlled regulator," Material Sciences and Application, vol. 2011, no. 2, pp. 859-869, 2011.

[7] J. Shipman, A. Hosangadi, and V. Ahuja, "Unsteady analyses of valve systems in rocket engine testing environments," in Proceedings of the 40th AIAA/ASME/SAE/ASEE Joint Propulsion Conference, Fort Lauderdale, Fla, USA, 2004.

[8] H. Ortwig and D. Hubner, "Investigation and CFD simulation of flow forces inside a mechatronic pressure controller for CNG engines," in Proceedings of the 12th Pan-American Congress of Applied Mechanics, Barcelona, Spain, 2012.

[9] B. K. Saha, "Numerical simulation of a pressure regulated valve to find out the characteristics of passive control circuit," International Journal of Mechanical, Aerospace, Industrial, Mechatronic and Manufacturing Engineering, vol. 7, no. 5, pp. 936-939, 2013.

[10] X. Du and S. Gao, "Numerical study of complex turbulent flow through valves in a steam turbine system," International Journal of Materials, Mechanics and Manufacturing, vol. 1, no. 3, pp. 301305, 2013.

[11] J. Yanping, S. Chibing, L. Lin, and L. Youpeng, "Simulation research on the dynamic processes of gas pressure reducing valve," in Proceedings of the 46th AIAA/ASME/SAE/ASEE Joint Propulsion Conference \& Exhibit, Nashville, Tenn, USA, July 2010. 


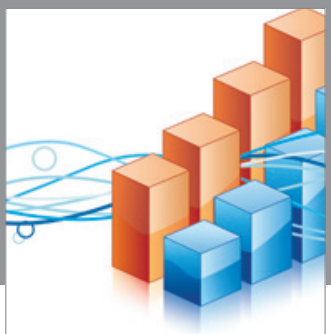

Advances in

Operations Research

vatem alat4

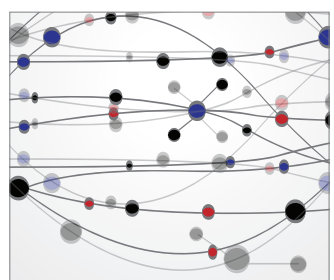

\section{The Scientific} World Journal
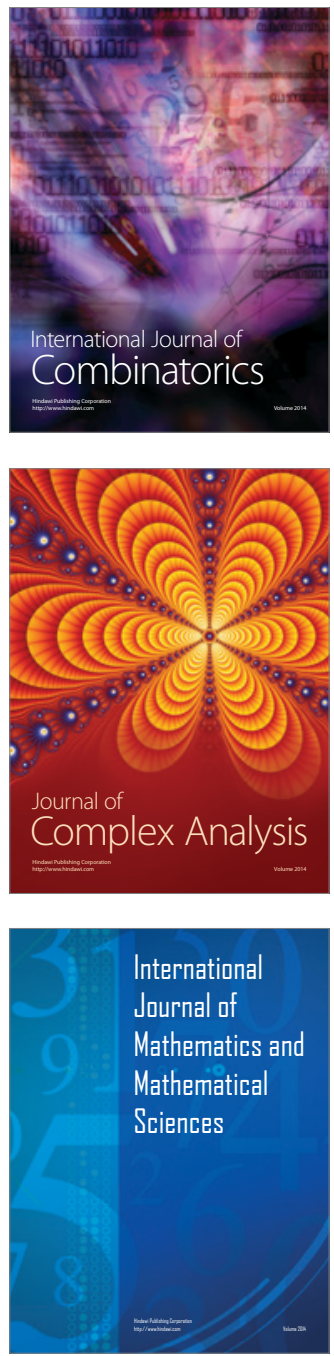
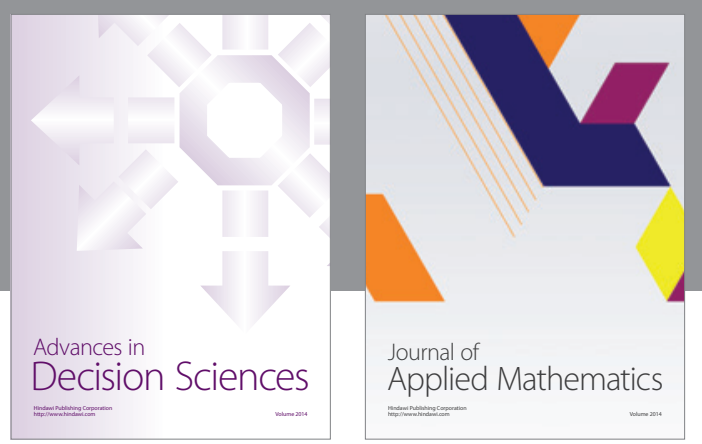

Algebra

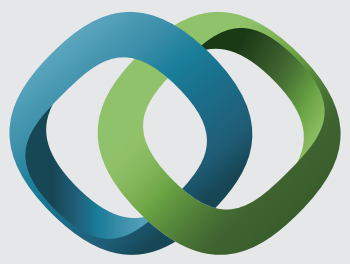

\section{Hindawi}

Submit your manuscripts at

http://www.hindawi.com
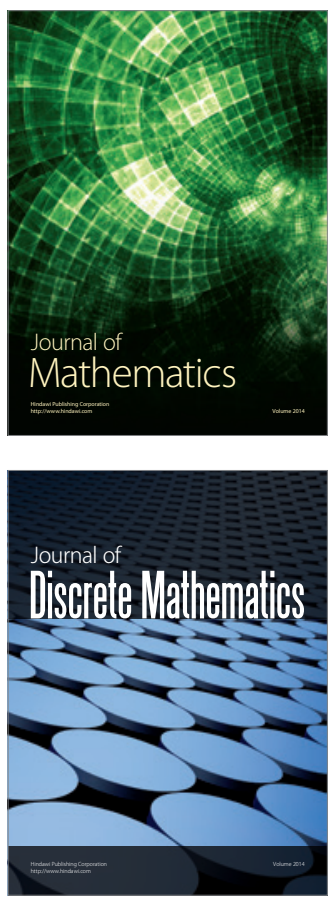

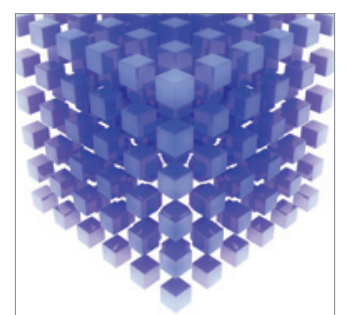

Mathematical Problems in Engineering
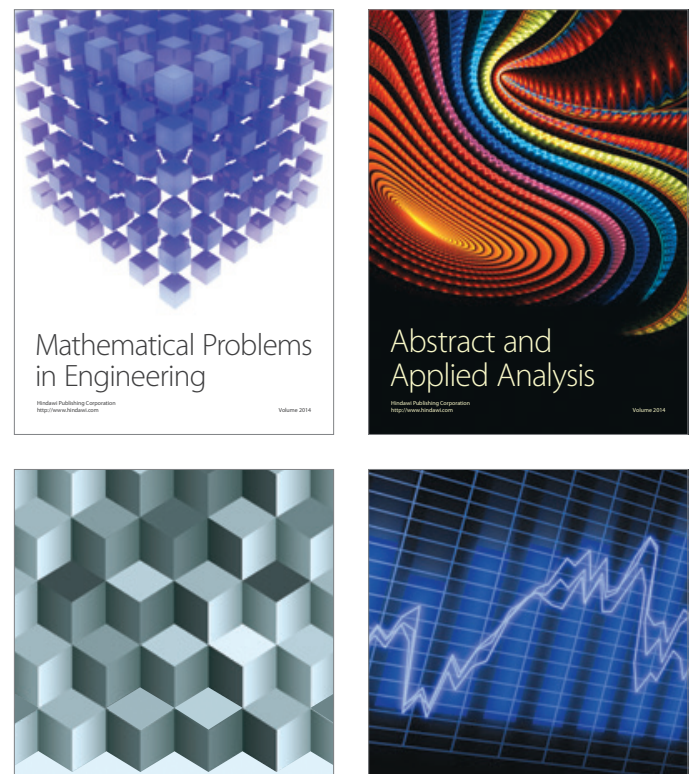

Journal of

Function Spaces

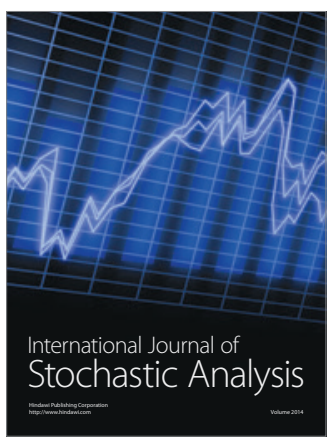

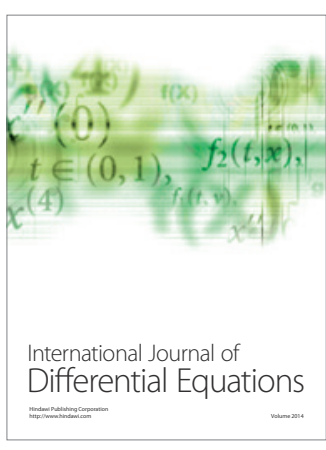
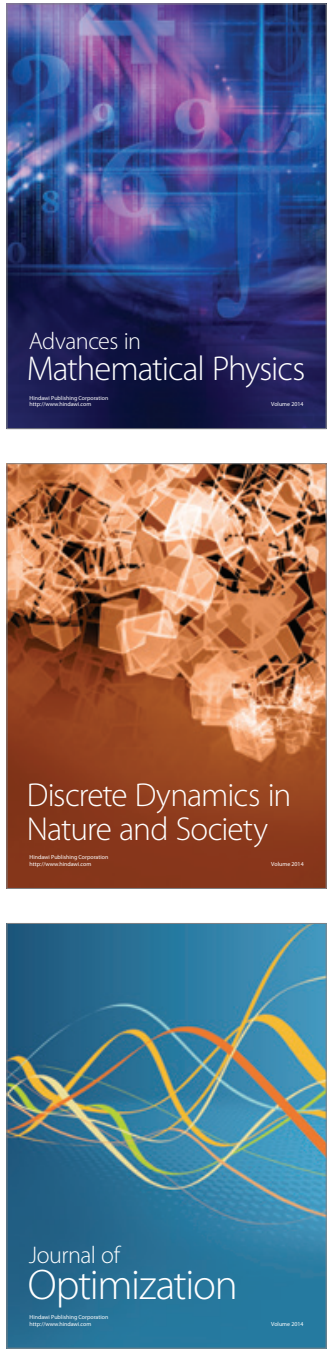